\title{
A process model for public sector IT management to answer the needs of digital transformation
}

\author{
Maija Ylinen \\ Tampere University of Technology \\ maija.ylinen@tut.fi
}

\author{
Samuli Pekkola \\ Tampere University of Technology \\ samuli.pekkola@tut.fi
}

\begin{abstract}
While organizations get prepared for digitalization, so must their IT departments. This means they have to increase their agility to respond to varying requests from different groups of users, increase infrastructure flexibility, and improve the utilization of the current resources. To answer these needs, traditional approaches and modes of IT management are often insufficient. We consequently propose a process model for public sector IT departments so that they can adjust their operations as a response to digitalization efforts, for example, smart cities and digital transformation. Our focus is especially on improving the IT development process within the organization, i.e., how the IT department can better respond to the needs of business units. Our findings show that the adjustments require changes both in management and daily operations. Moreover, changes should not be done only internally within the IT department, but also the whole organization should be involved.
\end{abstract}

\section{Introduction}

As information technologies (IT) advance at an ever-increasing pace [21, 36], many organizations have started to adopt them, and initiated a process of digital transformation. Digital transformation refers to a process where IT is applied in different areas of the organization with the intent to improve their operations [3]. In addition to providing new opportunities, new operational requirements emerge during the digital transformation [39]. This often makes traditional approaches to managing IT resources and providing services insufficient [3, 28]. Consequently, new challenges related to IT management have emerged $[22,34]$.

The change in the operational environment is taking place in both the private and public sectors. In this paper, we focus on the public sector, where municipalities, cities, agencies, and other public sector organizations have started to utilize different IT solutions to improve their customer service, cut costs, and gain greater efficiency [29]. So-called smart city endeavors are becoming common [11]. In municipalities, this means new ways to serve the citizens by providing digital services and increasing citizen involvement in governance [10].

Despite the well-reasoned objectives for new digitalization efforts, public sector organizations have not managed to utilize the full potential of IT applications [19]. One reason for this is that the IT departments are not always adequately equipped to provide and support business units with new technical solutions [49]. For example, greater agility is required from the IT departments to make them capable of responding to the rapid changes in the operational environment and in the customer needs [45]. Agility, however, is not typical in public sector organizations as they are hierarchical in structure and have a tendency to change slowly $[7,35]$. Nonetheless, as public sector organizations are implementing smart city projects and undergoing digital transformation [39], there is a need to develop approaches that enable public sector IT departments to adapt and adjust to the new requirements of their operational environment [28].

In this paper, we present one approach to cope with these issues. Our case is an IT department in a large municipality in Finland, which, during our research project, underwent an organizational transformation from a traditional, distributed IT department to an advanced but centralized unit in order to increase the speed of IT development process, improve customer services, and solve operational issues in a cost-efficient manner.

We seek answers to the following research question: How can a public sector organization organize its IT development process in response to digitalization? As an IT department is typically responsible for multiple tasks, such as administrating computers, maintaining old systems, and developing an organizational architecture [31], which require different activities and processes, we limit our focus only to the process of providing support for new customer needs, i.e., the IT development process. 
This paper is organized as follows. First, the role of the IT department and new requirements of their operations is identified from the literature. Then we proceed to research methods and settings, and present the findings from our case. Finally, the findings are reflected in the literature. The paper ends in conclusions.

\section{Background}

Traditionally, IT departments in both public and private organizations have been responsible for the following four tasks: running IT-related operations such as operating and administrating computers and networks; developing new systems and maintaining old ones; developing organizational architecture, referring to operations related to setting a strategy and providing frameworks and standards for system operations; and identifying business requirements [31]. Within these tasks, the IT departments' ultimate objective has been to ensure that IT could deliver business value [44].

After these early days, IT has become a more strategic asset for organizations [9, 26]. Instead of focusing only on managing their IT infrastructure, IT departments have adopted a new role in promoting digital innovation and business development [30]. They have become the drivers of the organization's digital transformation [20].

Digital transformation and digitalization refer to a process of utilizing different digital technologies to improve existing products and services, or producing new ones [17]. Digital transformation does not mean simply the digitalization of existing processes or services but a more fundamental change in processes and organizational mindset [43]. Overall, digital transformation requires profound changes in the business models of the organization, and its processes, resources, operational methods and objectives, and culture [22].

From the IT management point of view, this means new opportunities and challenges [23]. As [34] point out, the number of information systems (IS) and the level of their use has increased. Organizations have thus become more dependent on IT, which, in turn, have become more complex and more challenging to manage [18]. Also, organizations' business needs are changing rapidly [2]. To cope with these issues, IT departments need new practices, processes, and capabilities, so that they can support the organizations to benefit from the new technological advancements $[4,28,41]$. If it fails in this job, there is a significant risk that IT, instead of providing new opportunities, will become a hindering factor [34, 43].

For IT departments, this requirement to adapt to the requirements of digitalization is concretized, for example, through the need to increase operational agility. [28, 46] found that IT agility is one of the main drivers of the IT department's ability to support organizational digitalization. Agility and flexibility refer to the ability to easily combine complex IT systems with changes emerging unexpectedly, for example, in user needs, business processes, company structure, strategy, or from society $[36,45]$.

It is vital for IT departments to change their practices. This is because they do not cope well with rapid IT changes. For example, IT projects are notorious for delays and budget overruns as requirements and technologies can change during IT projects [2, 40, 47]. Hence, IT departments need to flexibly consider constantly changing technical and organizational issues in the development projects [27]. This requires a different attitude toward IT development, flexible IT infrastructure, and new working practices $[5,6,8,14]$.

In addition to the need for agility and flexibility in the development process, the literature has also argued for enterprise architecture (EA) being a precondition to successful digital transformation [45]. EA becomes critical since without proper foundations and comprehensive understanding about the IT infrastructure, the IT department's ability to deliver digital services is weak [28]. With properly defined processes, information systems, technologies and data, IT departments are equipped to find suitable solutions to arising needs [16]. With the understanding of EA, they can also suggest new services and not merely react to needs from elsewhere in the organization [15]. Hence, properly implemented EA improves the agility of IT departments.

The importance of adequate EA is emphasized [37]. [38] pointed out that recent (IT) architectural descriptions tend to be more problematic and complex than the ones created before the digitalization efforts took place. Consequently, when there is a strong infrastructure in place and the IT and business work as a partnership, it would be easier for the IT function to produce real business value [44].

All this points out the criticality of a shared mindset between business and IT. This allows essential changes in operations and supports sufficient utilization of the IT infrastructure [48]. Efficient collaboration between business and IT units is an enabler of organizational digitalization [20]. It not only enables better change management in IT projects but also helps with sensing the customer needs and responding to them. This interaction is critical to the creation of business value [42]. 


\section{Research settings and methods}

This study has been conducted as an interpretive qualitative single case study [50] in a municipality of 210,000 inhabitants and 10,600 employees in Finland. We study a change process in the municipality's IT department with 45 people.

The IT department was struggling with the change in its operational environment where new IT needs are emerging at an ever-increasing pace, and the number of ongoing acquisitions of new IS are growing. We studied their efforts to adapt and adjust to the new requirements, which they did by significantly changing their working practices and processes. This particular case was selected as the municipality's issues with the IT development were commonly known, discussed, and awarded in the Finnish press, and as it was currently conducting a radical change in its operations.

We focus especially on the changes of the IS development process. During the time of data collection from January 2017 to December 2017, the organization had designed and implemented, with a consultancy agency, a new organizational structure and development process.

The data were collected using a semi-structured open interview method. The interviews followed the same protocol although we emphasized the issues with which the interviewees were knowledgeable and interested. All interviews were audio-recorded and transcribed.

We interviewed 17 individuals involved in the design and implementation of the reorganization (see Table 1). Six interviewees were interviewed twice, first at the beginning of the year when the change process was started and the initial situation was studied, and second at the end of the year when the new process had been in use for two months. Then the focus was on the results of the change. Throughout the study, we, the researchers, acted as outside observers. To gain a comprehensive understanding of the situation before the change, an IT procurement project was also included as an example. The project was selected as being considered as a representative case.

We supplemented the interviews by analyzing different models and diagrams on the new development process, provided by the consultancy agency. During our visits to the IT department, we were also able to observe the slide shows and physical Kanban board, located in the common area of the office.
Table 1 Interviewees

\begin{tabular}{|l|c|}
\hline Interviewee & No of interviews \\
\hline CIO & 2 \\
\hline Development manager & 1 \\
\hline Architecture team manager & 1 \\
\hline Project manager & 1 \\
\hline Head of account managers & 1 \\
\hline Account manager A & 1 \\
\hline Account manager B & 1 \\
\hline Project manager & 1 \\
\hline Consultant A & 2 \\
\hline Consultant B & 2 \\
\hline Consultant C & 2 \\
\hline Consultant D & 1 \\
\hline Social and health services specialist & 1 \\
\hline Department head & 1 \\
\hline Head nurse & 1 \\
\hline Main architect & 2 \\
\hline Enterprise architect & 2 \\
\hline
\end{tabular}

The data were analyzed inductively, using a datadriven approach [50]. The process of analysis is presented in Figure 1. We started the analysis by constructing the old and new IT development process models from the interviews and models and diagrams. After this, different problems in the old process model were identified from the interviews, reflected in the new model, and analyzed whether they were actually solvable or solved. Although the organizational change has officially been finalized, the IT department applies a continuous development approach.

\section{Findings}

\subsection{Initial situation}

There were multiple challenges, initiating the organizational change, in the municipality and its IT department. First, the IT department had very slow internal operations, leading to slow service times, IT development, and business unit dissatisfaction. Existing IT resources were poorly managed due to a poorly implemented EA approach. This resulted in insufficient use of existing resources. Finally, the collaboration with business units and other customers of the IT department was defective.

Slow internal operations: One significant operational problem was the lack of explicitly assigned decision-making power: "[earlier] there was actually nothing, things just came from here and there" [Consultant A]. As a result, many topics were presented to the IT steering group, which, however, was not knowledgeable about the reasons behind the issues, because of their distance from daily operations. 


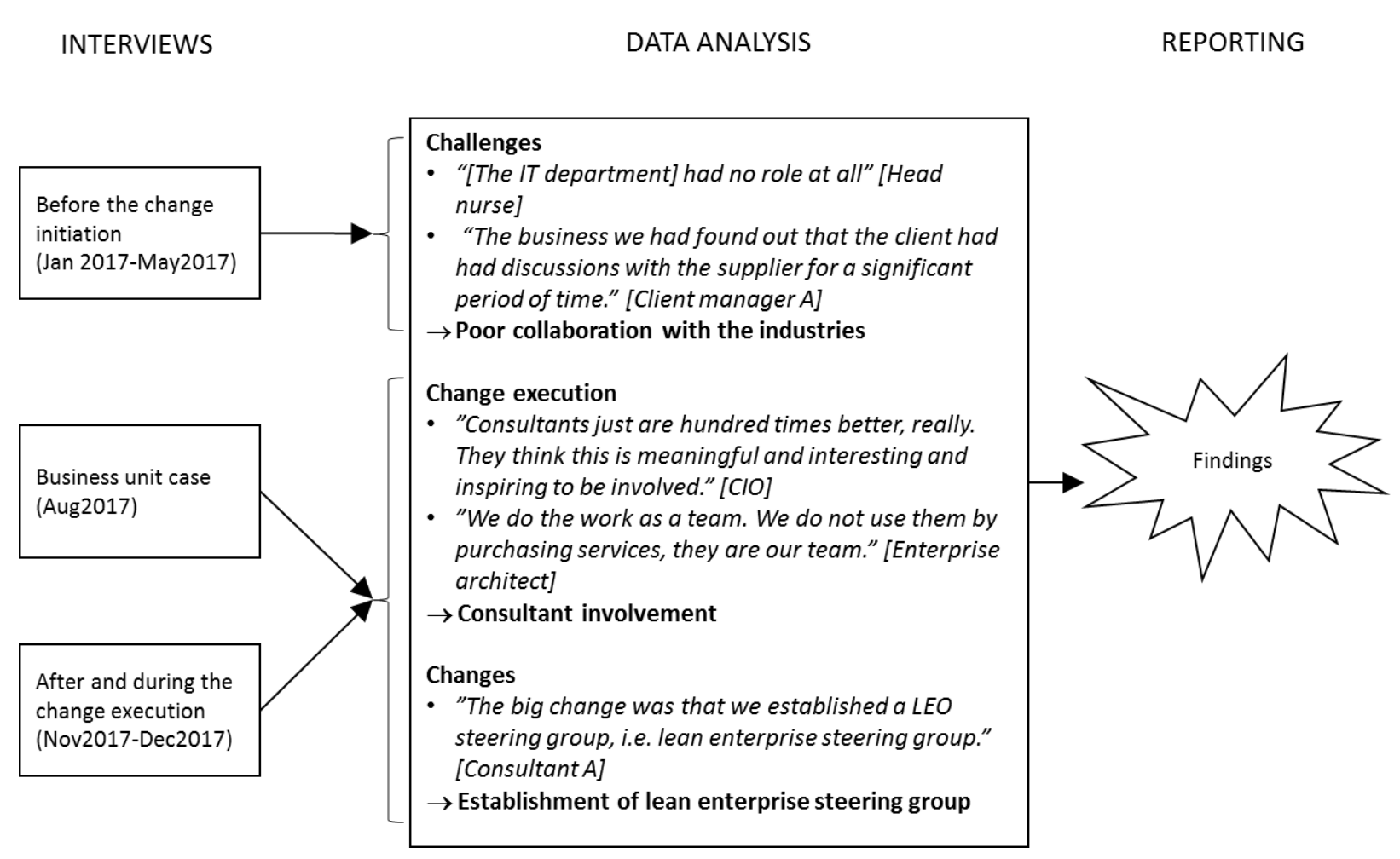

Figure 1 Data collection and analysis process

The IT steering group was thus inefficient as it could not focus on financial issues and decisions but had to address operational matters as well. This delayed the decisions from being made as quickly as would have been beneficial, even though the decisions were always positive. This indecisive and inefficient process slowed the IT department's development operations significantly.

Development projects were also slowed down by a lack of knowledge related to the skills, competences, and knowledge of employees in the business units. Consequently, significant amounts of time were lost since people had to search for the individuals with the appropriate knowledge. In many cases, neither the individual nor knowledge existed, but the information had to be created.

The IT department was also struggling with its inability to spend the money and resources allocated to its development processes. In most cases, the IT development was about procuring IT. Due to the tendency of public sector procurements to end up in the juridical process, the procurement projects were regularly prolonged. However, the IT department had no adequate system to reutilize money and resources while waiting for court decisions. "Let me say that we have saved a lot as we have not been able to use [budget] the way we wanted [and planned]" [development manager]. The result of all this was that the procurement process was inefficient and made the IT department's productivity look very alarming. It simply seemed that they were not doing anything as no money was spent and no results achieved.

Poor IT resource management: Besides difficulties with extremely slow operations, the IT department was struggling with a poor understanding of their existing IT infrastructure and resources. This lack of understanding led to a tendency to acquire new IT systems even when there were existing ones providing similar functionalities or solutions elsewhere in the municipality.

The EA team at the municipality caused another problem. The team was established to support the IT projects and to provide an overview of the existing resources and IT infrastructure. However, their work mainly focused on acquiring reference architectures from outside consultants, and conducting project auditions. "We made reference architectures and architectural documents [. . .] then these documents were presented to the projects and the project manager. After this, we left them to manage the documents by themselves" [architecture team manager]. The IT department had consequently invested in improving its ability to utilize existing IT resources but failed badly. The EA team was just causing costs but providing few benefits. 


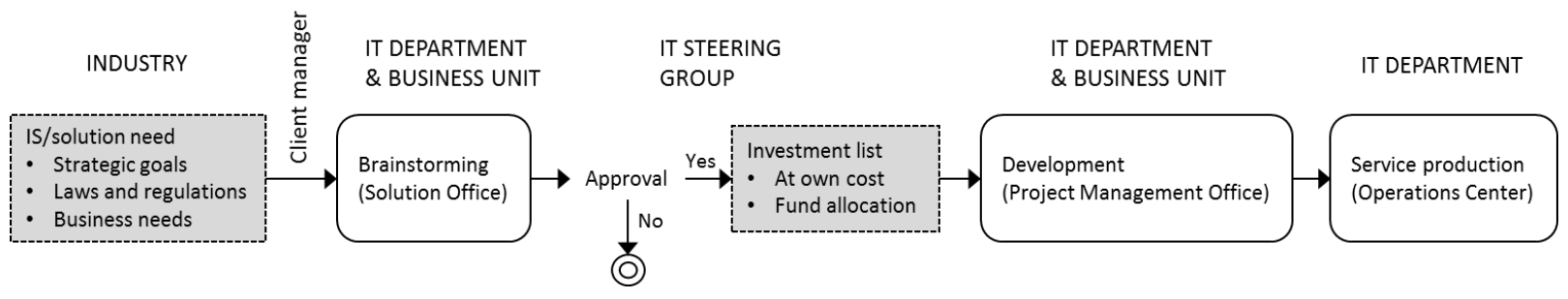

Figure 2 The new development process

Due to the issues with EA, there was no proper planning for the future. New systems were acquired when new needs emerged. It was thought that the IT steering group would evaluate the strategic value of the proposed investment; it was not done sufficiently. IT resource management in general seemed to be random.

Poor collaboration with the business units: In addition to the internal issues, the IT department suffered from significant problems with their customer collaboration. Due to poor collaboration, the business units perceived that they were not properly supported. Slow development processes did not ease the situation.

The slowness of the IT departments' processes was the key issue in improving customer service and collaboration. This problematic situation resulted in the business units avoiding involving the IT department in their IT development ideas as long as possible. The business units independently prepared and drafted the outline of the system they wanted, surveyed potential suppliers, and invented the way to implement the system. Consequently, procurement plans and proposals presented to the IT steering group were prepared by the business units themselves. However, although the business units had domain knowledge of their field, they had little understanding of IT. IT issues were thus underrated in the investment proposals. The IT department had little to no influence on the requirements specification, or chances to evaluate how well the system would fit with existing IT infrastructure.

\subsection{New approach}

To address these challenges, the $\mathrm{CIO}$ initialized an organizational change project. He hired assistants from an external consultancy office. They developed a new process, which is presented in Figure 2.

In the first step, when the needs of the business units emerge, the business unit is expected to contact their assigned account manager at the IT department. The account manager will then present the need to IT department's new Solution Office, where the need is evaluated. A solution is then refined with the business unit customer and the IT department's specialist, knowledgeable on those particular needs and solutions.
Brainstorming sub-process at the Solution Office is presented in Figure 3.

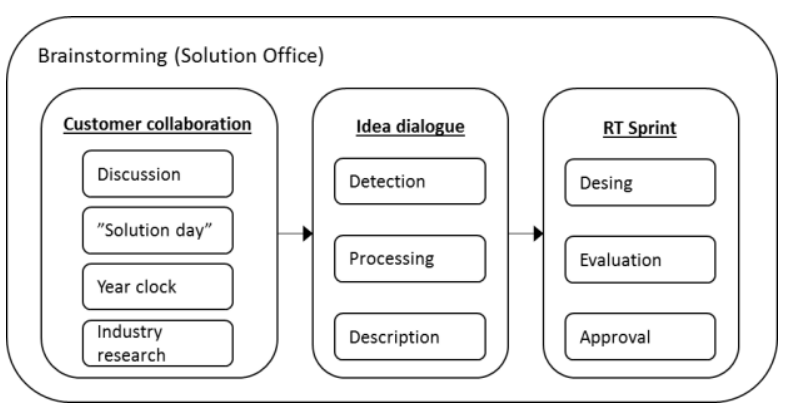

Figure 3 Detailed brainstorming process

In the brainstorming stage, the need is first analyzed in-depth in collaboration with the customer (business unit representative). In addition to normal discussions and debates, this analysis includes "a solution day", where the business unit representatives, i.e. the end users of the new system, meet with the IT department people to share thoughts about the needs and expectations. The extent of the solution day is dependent on the scale of the potential solution. The urgency is then considered in relation to the business unit's year clock phase, i.e. is there a certain time when the solution implementation can/cannot be made (c.f. [24]). Then a person at Solution Office conducts a business unit research to find out if other units have solved that particular problem. The brainstorming proceeds to idea dialogue where different alternatives are detected, processed and described. In the real time (RT) Sprint phase, they are further elaborated and evaluated. Typically, three alternatives are approved and presented to the business unit for their selection.

The selected solution is then taken to the IT steering group, where the investment decision is made. If the business unit has saved, secured, or obtained financial resources, they might be given permission to implement the solution in collaboration with the IT department immediately. If there is no funding but the solution is considered to be essential, it is included in the investment list to wait for funding and other resources.

After this point, the new process follows the old one. A development project is created, and a team is 
gathered. After the project ends, the solution, typically an IS, is used by the customer and maintained by the Operations Center at the IT department.

\subsection{Main changes in the processes}

Although there were several changes in the IT development process, six stood out in the interviews. They are presented next.

Establishing a lean enterprise steering group: The new steering group was established to speed up the decision-making at the IT steering group by moving operational decisions to the new group. This new lean enterprise steering group was expected to solve some of the power and responsibility issues in the IT department, because now there was a place where emerging IT specific issues could be solved. However, at the time of the interviews, it was still unclear how much decision-making power the lean enterprise steering group would actually gain. This is because the decision-making process related to large IT investments requires acceptance not only from the IT steering group, but also from the municipality's management group, where the mayor has the final word. This is a process that cannot be changed by the IT department.

Appointing a development manager: The $\mathrm{CIO}$ appointed a new management role, a development manager, in his management team. His responsibility was to gain an overview of the IT development process and its bottlenecks, and speed it up. The development manager was also expected to improve the use of funding and other resources in the procurement processes.

Establishing a Solution Office: In the change process, the focus was mainly on reorganizing the first phases of the IT development process. For this purpose, the IT department created a virtual team, referred to as the Solution Office, whose main task was to design and develop solutions to the needs from the business units, delivered by the business unit's customer specialist. This process was described earlier and presented in Figure 3. Due to the municipality's human resource policies, the CIO was not able to establish a new team with new employees. Consequently, the Solution Office was virtual, with an appointed leader but part-time members from other units at the IT department, recruited according to the needs of each proposal. The objective of the team was to encourage the business units to contact the IT department as early as possible with their new IT development proposals.

Adopting new work management approaches: Besides changes in the IT department's process structures, also their daily operations were changed.
One of these changes was the introduction of lean thinking [13]. IT teams, especially the Solution Office, started to use the Kanban approach [1], where all suggestions, ideas, projects, and their progress were presented. Teams also adopted the practice of regular Scrum meetings [25]. In addition, the office space was converted into an open office to support better collaboration and knowledge transfer between employees.

Removal of EA reviews and the integration of the architects with the development process: The role of enterprise architects was significantly changed. The EA review team, responsible for auditing the IS projects, was disbanded and mainly expelled. The remaining architects were included in the new Solution Office. This way they were involved in new projects from the very beginning. The architects had better chances to assist the projects, where they were now welcomed as the benefit of having an architect became evident. The municipality also hired more enterprise architects to make sure that they were able to be involved in critical projects and assist different business units with the creation of digitalization strategies.

Initializing digitalization strategy work with the business units: The latest effort to improve collaboration with business units and planning for the future, the IT department started to encourage and assist the business units in creating their own digitalization strategies. So far, this has taken place mainly in the municipality-owned corporations, but there is a growing interest also among other business units, such as in health care. Because of this, the implications are still unknown. However, in the interviews, the CIO, main architect, and consultant responsible for digitalization considered this as a significant step toward the planned and strategic digitalization efforts.

\section{Discussion}

We will next discuss the issues from two perspectives, the new process model, and generic lessons learned.

\subsection{Evaluation of the new process}

There were several problems at the IT department before the process renewal. Most severe were the need to increase the speed of the IT development process, improve customer services, and solve operational issues such as a lack of explicitly defined responsibilities and insufficient usage of existing resources. 
Our findings indicate positive effects on operational challenges and poor IT resource management. For example, the interviewees felt that information sharing and collaboration inside the IT department have improved significantly. Also, the enterprise architects' involvement in the IT development had been enhanced.

However, the changes did not resolve all the critical issues disclosed in the interviews. For example, the changes did not take into consideration the issues with the customers or the main bottleneck of the development process, i.e., the slowness of the investment acceptance. Customer collaboration still remains the responsibility of the account manager. Since the customers were unsatisfied with them already before the change, the changes neither improved nor diluted these relationships. It is consequently not guaranteed that the situation will improve in the future.

On the other hand, the IT steering group and municipality's management group are still responsible for the investment decisions related to development projects. While the lean enterprise steering group can take over many operational decisions and background checks, it is unknown whether this will actually speed up the decision process. Even before the change, the management group focused first on the most important decisions, meaning that the operational decisions were typically postponed. Consequently, although the process change improved operational issues in the IT department, it did not speed up the decision-making process. This was one of the main objectives of the organizational change.

It can be questioned whether the IT department actually focused on the main problems of the development process. The new model emphasizes planning at the early phases of the IT development projects and proposals. Yet it is questionable how this planning contributes to the IT procurement, which has been identified as challenging [32, 33, 38]. The process renewal did not consider these issues, although it was acknowledged in the interviews.

It is very difficult to solve several challenges simultaneously, with only one model. This is concretized especially when multiple stakeholders are involved. As [20] point out, it is essential that IS and business leaders share similar mindsets and goals for making the adaptation of new technologies and processes possible. In municipality settings, this is often very difficult, as, for example, investment decisions are political and the $\mathrm{CIO}$ as a public officer cannot make them by him/herself $[12,48]$. This is a topic with which they will most likely struggle during their digital transformation endeavors. This, however, does not remove the need to improve the operations.

Many topics in the change process can be considered successful. When the outcomes of the change are initially evaluated, it seems that one reason for the seeming success is that the IT department did not actually solve the difficult issues. For example, customer collaboration, which is identified as a critical aspect in digital transformation, is still problematic. Operational agility and flexibility improved, but because the changes were targeted and conducted only within the IT department, it remains unclear whether the actions actually had an impact on the other parts of the organization. These initial results need to be sufficiently evaluated after the new process has been in use longer. The process model needs also to be implemented elsewhere so that its generalizability can be assessed.

\subsection{Lessons learned}

Initially the change project aimed at integrating the EA approach with the IT development process. This triggered more changes, and resulted in redesigning the whole IT development process. However, EA issues, enforced by national legislation, created a feeling of urgency of change. This feeling was then used as an excuse to make broader changes at the IT department, and succeed there (c.f. [51]).

One explanation for the success of this approach, as the CIO articulated, was that the development and implementation of the new process would never finish. The current process model, presented in Figure 2, is only their latest version, which was revised and updated numerous times during the change process whenever new needs emerged, to be revised and updated regularly also in the future.

It seems that the interviewees were happy with this type of approach. The employees at the IT department seem to have found an atmosphere where they have started to believe that if new issues emerge, they will be considered and solved. This greatly contradicts the original situation where the problems were overlooked and accepted as they were. Consequently, a continuous development approach was perceived as appropriate.

Altogether, the changes were not small. Although the basic tasks did not change, the ways they are organized, executed, and reported did. This emphasizes that the change needs also to be (made) visible in daily tasks, not only in the structures or in the process descriptions. To change the atmosphere and attitudes in the IT department, it was necessary to change the way people collaborated within and outside the IT department.

In this case, the consultants also played a significant role in enabling and promoting the change. As they were not contaminated with the organization's former manners and bad culture, they were eager to improve the operations and try something new. They 
acted as change agents, examples, and good leaders for the IT department. Obviously, those IT workers whose work the consultants attempted to change radically opposed the idea. For example, enterprise architects constantly questioned the usefulness of the consultants.

The CIO supported the use of consultants even though they were up to one third of the whole workforce in the IT department. His commitment to the change and trust toward the consultants was an important factor, demonstrating the importance of management's commitment to organizational change.

Despite the success in changing the atmosphere in the IT department, the external stakeholders and their lack of commitment, for example, as well as the absence of business unit representatives, hindered the change initiative as a whole. In December 2017, at the time of the last interviews and more than a year after the beginning, the IT department was still struggling to gain commitments from the business units to their new operations and practices. There were still situations in which the business units did not involve the IT department in their IT proposals. Gaining the commitment from all business units remains a task for the future.

Consequently, many aspects affect the success of the change initiative. For example, urgency to change (disbanding the EA team), continuous development of the new process model, alterations in managing the work practices and daily operations, the CIO's commitment, and the consultants' eagerness to help played a significant role. However, as the issues with the business units underline, the IT department can still improve the way it operates during the organizational changes. In this case, the lack of business unit involvement was the most obvious source of problems. As the business units were not properly considered and involved, they were not ready to commit to the new way of operations. What the consequences of this will be, remains to be seen later.

\section{Conclusion}

Digitalization creates new opportunities to organize work and generate business with both private and public sector organizations [29]. To capitalize these opportunities, organizations need to be ready to adjust their operations appropriately, and meet the need of the new environment. This becomes critical especially for the IT departments, which need to be able to respond to the changing customer needs and business opportunities.

In this paper, we have studied organizational change in a public sector IT department in Finland. We have illustrated that digitalization can create and raise numerous challenges, which can rarely be improved and solved by simple activities. More fundamental changes to daily operations, collaboration practices with every possible stakeholder, and the division of responsibilities are required. There is also a need to improve the integration of IT projects between different sections of the organization.

Our rather generic process model can be more easily implemented in other organizations. In so doing, our lessons learned will help organizations to improve their readiness to adapt to the new requirements of digitalization. This underlines our two-fold contributions. First, our process model answers the needs of digital transformation. It will help not only public sector IT management but may also help the private sector when they design and develop their own practices and processes. Second, our lessons learned become valuable for refining this model, and implementing it or other IT management models to other contexts. Especially the broadness of the change in the IT department, so that it touches all business units, and makes the change difficult to plan, design, and execute. These issues are directly usable by practitioners, but also researchers benefit from them when developing new frameworks and instructions, and possibly theorizing the change.

Our main limitation is the fact that the findings are based on a single case study. This means that the findings should be generalized cautiously. We are thus not claiming that these actions would solve all digitalization challenges in every organization. Instead, they should be applied after analyzing the new context. More research is obviously needed on this little-studied topic. This is acknowledged also in our case organization and in our future work, when we will assess the model and lessons after the new operation model has been in use for a longer time, almost another year. After this assessment, we can more strongly argue for the applicability of the model to other organizations. Both the consultants and our case organization have shown interest in disseminating the process model and the lessons they have learned to Finland, and further across Europe, where many public sector organizations are all trying to benefit from digitalization. After all, digital transformation will touch more and more organizations in the future.

\section{Acknowledgements}

This study was funded by the Academy of Finland grant \#306000.

\section{References}

[1] Ahmad, M.O., J. Markkula, and M. Oivo, "Kanban in software development: A systematic literature review", 
Software Engineering and Advanced Applications (SEAA), 2013 39th EUROMICRO Conference, 2013, pp. 9-16.

[2] Benamati, J., and A.L. Lederer, "Coping With Rapid Changes in It.", Communications of the ACM 44(8), 2001, pp. 83-87.

[3] Berman, S.J., "Digital transformation: opportunities to create new business models", Strategy \& Leadership 40(2), 2012, pp. 16-24.

[4] Bharadwaj Anandhi, E.S.O. A., and P.A. Pavlou, "Digital Business Strategy: Towards a Next Generation of Insight", MIS Quartely 37(2), 2013, pp. 471-482.

[5] Bhatt, G., A. Emdad, N. Roberts, and V. Grover, "Building and leveraging information in dynamic environments: The role of IT infrastructure flexibility as enabler of organizational responsiveness and competitive advantage", Information and Management 47(7-8), 2010, pp. 341-349.

[6] Bogucki, N., "Capturing flexibility of information technology infrastructure: A study of resource characteristics and their measure", Journal of Management Information Systems 12(2), 1995, pp. 17.

[7] Boyne, G.A., "Public and private management: what's the difference?.", Journal of management studies 39(1), 2002, pp. 97-122.

[8] Byrd, T.A., and D.E. Turner, “An exploratory analysis of the value of the skills of IT personnel: Their relationship to IS infrastructure and competitive advantage", Decision Sciences 32(1), 2001, pp. 21-47.

[9] Carr, N.G., "IT Doesn't Matter", Harvard Business Review, 2003, pp. 5-17.

[10] Carter, L., and F. Bélanger, "The utilization of egovernment services: Citizen trust, innovation and acceptance factors", Information Systems Journal 15(1), 2005, pp. 5-25.

[11] Cocchia, A., "Smart and Digital City: A Systematic Literature Review", In Smart City Progress in IS. 2014, pp. 13-43.

[12] Dingsoyr, T., G.K. Hanssen, T. Dyba, G. Anker, and J.O. Nygaard, "Lecture Notes in Computer Science", 7th International Conference, EGOV, 2008, pp. 5-15.

[13] Ebert, C., P. Abrahamsson, and N. Oza, "Lean software development", IEEE Software 29(5), 2012, pp. 22-25.

[14] Fink, L., and S. Neumann, "Exploring the perceived business value of the flexibility enabled by information technology infrastructure", Information and Management 46(2), 2009, pp. 90-99.

[15] Foorthuis, R., M. van Steenbergen, S. Brinkkemper, and W.A.G. Bruls, "A theory building study of enterprise architecture practices and benefits", Information Systems Frontiers 18(3), 2016, pp. 541-564.

[16] Frampton, K., G. Shanks, T. Tamm, S. Kurnia, and S. Milton, "Enterprise Architecture Service Provision: Pathways to Value", Twenty-Third European Conference on Information Systems (ECIS), 2015, pp. 1-9.

[17] Gartner, "Digitalization", Gartner IT glossary and A Dictionary of Business and Management, 2018.

[18] Gerth, A., and S. Rothman, "The future IS organisation in a Flat World", Information Systems Management 24, 2007, pp. 103-111.

[19] Hackney, R.A., and N.K. McBride, "The efficacy of information systems in the public sector: issues of context and culture", International Journal of Public Sector Management 8(6), 1995, pp. 17-29.

[20] Hansen, A.M., P. Kraemmergaard, and L. Maghiassen, "Rapid Adaptation in Digital Transformation: A Participatory Process for Engaging IS and Business Leaders", MIS Quarterly Executive 10(4), 2011, pp. 175-186.

[21] Hauder, M., S. Roth, F. Matthes, and C. Schulz, "An Examination Of Organizational Factors Influencing Enterprise Architecture Management Challenges", 21st European Conference on Information Systems (ECIS), 2013, Paper 175.

[22] Henriette, E., M. Feki, and I. Boughzala, "Digital Transformation Challenges", Mediterranean Conference on Information Systems (MCIS), 2016, pp. 1-7.

[23] Janssen, M., Y. Charalabibis, G. Kuk, and T. Cresswell, "E-government interoperability, infrastructure and architecture: State-of-the-art and challenges", Journal of Theoretical and Applied Electronic Commerce Research 6(1), 2011.

[24] Kankaanpää, I., and S. Pekkola, "Timing the information system upgrade", Proceedings of the 18th European Conference on Information Systems (ECIS2010), 2010, pp. 83-91.

[25] Kern, J., K. Beck, W. Cunningham, A. van Bennekum, and A. Cockburn, "Manifesto for Agile Software Development", 2000, 10. http://agilemanifesto.org/

[26] Kien, S.S., C. Soh, and M.L. Markus, "A new IT organizational form for multinational enterprises", Proceedings - Pacific Asia Conference on Information Systems, (PACIS) 2013.

[27] Lee, G., and W. Xia, "The ability of information systems development project teams to respond to business and technology changes: A study of flexibility measures", European Journal of Information Systems 14(1), 2005, pp. 75-92.

[28] Leonhardt, D., I. Haffke, J. Kranz, and A. Benlian, "Reinventing the IT Function: The Role of IT Agility and IT Ambidexterity in supporting Digital Business Transformation", Proceedings of the 25th European Conference on Information Systems (ECIS), 2017, pp. 968984.

[29] Liu, S.M., and Q. Yuan, "The Evolution of Information and Communication Technology in Public Administration", Public Administration and Development 35, 2015, pp. 140151.

[30] Matt, C., T. Hess, and A. Benlian, "Digital Transformation Strategies", Business and Information Systems Engineering 57(5), 2015, pp. 339-343.

[31] McNurlin, B.C., and R.H. Spraque, Information Systems Management In Practice, New Jersey, 2006.

[32] Moe, C.E., and T. Päivärinta, "Challenges in Information Systems Procurement in the Public Sector", Electronic Journal of e-Government 11(1), 2013, pp. 307322.

[33] Moe, C.E., A.C. Risvand, and M.K. Sein, "Limits of Public Procurement: Information Systems Acquisition", EGOV, 2006, pp. 281-292.

[34] Möller, D., and A. Heck, "Understanding IT transformation - an explorative study", European Conference on Information Systems (ECIS), 2011, Paper 15.

[35] Nasim, S., and Sushil, "Managing continuity and 
change: a new approach for strategizing in e-government", Transforming Government: People, Process and Policy 4(4), 2010, pp. 338-364.

[36] Nazir, S., and A. Pinsonneault, "IT and Firm Agility: An Electronic Integration Perspective", Journal of the Association for Information Systems 13(3), 2012, pp. 150 171.

[37] Van Oosterhout, M., E. Waarts, and J. Van Hillegersberg, "Change factors requiring agility and implications for IT", European Journal of Information Systems 15(2), 2006, pp. 132-145.

[38] Pan, G.S.C., "Information systems project abandonment: A stakeholder analysis", International Journal of Information Management 25(2), 2005, pp. 173-184.

[39] Parviainen, P., M. Tihinen, J. Kääriäinen, and S. Teppola, "Tackling the digitalization challenge: how to benefit from digitalization in practice", International Journal of Information Systems and Project Management 5(2), 2017, pp. $1-88$.

[40] Pekkola, S., E. Niemi, M. Rossi, M. Ruskamo, and T. Salmimaa, "ERP Research at ECIS And ICIS: A Fashion Wave Calming Down?", Proceedings of the 21st European Conference on Information Systems (ECIS), 2013, Paper 123.

[41] Rai, A., P.A. Pavlou, and S. Du, "Interfirm It Capability $\mathrm{P}$ Rofiles and Communications for Cocreating R Elational Value : Evidence”, MIS Quartely 36(1), 2012, pp. 233-262.

[42] Ravi, A., R. Patnayakuni, and N. Seth, "Firm Performance Impacts of Digitally Enabled Supply Chain Integration Capabilities", MIS Quarterly 30(2), 2016, pp. 225-246.

[43] Riedl, R., A. Benlian, T. Hess, D. Stelzer, and H. Sikora,
"On the Relationship Between Information Management and Digitalization", Business \& Information Systems Engineering 59(6), 2017, pp. 475-482.

[44] Ross, J.W., C.M. Beath, and D.L. Goodhue, "Reinventing the IS Organization: Evolution and Revolution in IT management Practices", Center for Information Systems Research, 1994, CISR WP No. 266.

[45] Salmela, H., T. Tapanainen, A. Baiyere, M. Hallanoro, and R. Galliers, "IS Agility Research: An Assessment and Future Directions", European Conference on Information Systems (ECIS), 2015.

[46] Sambamurthy, Bharadwaj, and Grover, "Shaping Agility through Digital Options: Reconceptualizing the Role of Information Technology in Contemporary Firms", MIS Quarterly 27(2), 2003, pp. 237-263.

[47] Shaul, L., and D. Tauber, "Critical success factors in enterprise resource planning systems", ACM Computing Surveys 45(4), 2013, pp. 1-39.

[48] Tanriverdi, H., A. Rai, and N. Venkatraman, "Reframing the dominant quests of information systems strategy research for complex adaptive business systems", Information Systems Research 21(4), 2010, pp. 822-834.

[49] Torres, L., V. Pina, and S. Royo, "E-government and the transformation of public administrations in EU countries", Online Information Review 29(5), 2005, pp. 531-553.

[50] Walsham, G., "Doing interpretive research", European Journal of Information Systems 15(3), 2006, pp. 320-330.

[51] Ylinen, M., and S. Pekkola, "ENTERPRISE ARCHITECURE - EASY SCAPEGOAT OF CHANGE?", International Conference on Information Systems (ICIS), 2018 . 